\title{
The Explanatory Power of Deflationary Truth
}

\author{
Darren Bradley ${ }^{1}$ (D)
}

Received: 27 August 2020 / Accepted: 23 December 2021

(c) The Author(s) 2022

\begin{abstract}
It is widely believed that deflationary truth has no explanatory power. I will argue that it does. Specifically, I will consider some objections to deflationary truth having explanatory power, and argue that they fail. The position which will emerge is that the deflationary concept of truth is analogous to the concept of an average. Scientists take averages to be explanatory, and I will argue that the concept of deflationary truth is explanatory in the same way. I then argue that this deflationary concept of truth motivates a theory of the property of truth which is metaphysically disunified, but that this is no obstacle to explanation. This leads to a way of understanding the deflationary/substantive distinction in terms of grounding.
\end{abstract}

\section{Introduction}

Many proponents and critics of deflationism agree that deflationary truth has no explanatory power. I will argue that it does-deflationary truth is explanatory. Specifically, I will consider some objections to deflationary truth having explanatory power, and argue that they fail. The position which will emerge is that the deflationary concept of truth is analogous to the concept of an average. Scientists take averages to be explanatory, and I will argue that the concept of deflationary truth is explanatory in the same way. I will then argue that this deflationary concept of truth motivates a theory of the property of truth which is metaphysically disunified, but that this is no obstacle to explanation. This leads to a way of understanding the deflationary/substantive distinction in terms of grounding.

I will take for granted the following deflationary theory of the concept of truth:

Deflationary Theory of the Concept of Truth

The entire conceptual and theoretical role of the concept of truth may be explained on the basis of the Minimalist Theory (MT):

Darren Bradley

bradleydarren@gmail.com

1 Philosophy Department, Leeds University, Woodhouse Lane, Leeds LS2 9JT, UK

Published online: 13 February 2022 
(MT) The proposition that quarks exist is true iff quarks exist, the proposition that lying is bad is true iff lying is bad, . . . and so on

Many philosophers connect this minimalist theory of the concept with the thesis that the concept is not explanatory. I will argue that these theses not only can, but must come apart. I will argue from the minimalist theory of the concept of truth to the view that the concept of truth is explanatory. I will identify three reasons for thinking that deflationary truth is not explanatory (or never part of the best explanation) and argue that none are convincing. The upshot is that the standard taxonomy which contrasts substantive explanatory truth with deflationary non-explanatory truth is confused.

Section 2 gives some background on deflationism and the challenge of the Success Argument. Sect. 3 gives some background on explanation, raising the question of whether the deflationary concept of truth can be explanatory. Section 4 argues that averages can be devices for expressing infinitely long sentences and can be explanatory. Section 5 develops the analogy between averages and deflationary truth. Section 6 responds to Gupta's (1993) development of the Success Argument against deflationism. Section 7 discusses the objection that the property of truth is disunified. I will give a theory of unification in terms of grounding and argue that the concept of a disunified property can be explanatory. Section 8 discusses the fall-back position that the concept of deflationary truth gives explanations which are inferior to alternatives, and argues that the concept of deflationary truth abstracts away from details, which can improve the quality of the explanation. Section 9 concludes.

\section{The Deflationary Concept of Truth and the Success Argument}

Gupta (1993) writes:

A deflationary view typically consists of two parts:

i. a description of the meaning and function of 'true' and

ii. a derivation from that description of deflationary consequences concerning truth. p.58

Part (i) typically involves the claim that the concept of truth is a device for expressing an infinitely long sentence, or an infinite number of sentences. Quine (1970) writes:

We may affirm the single sentence by just uttering it, unaided by quotation or by the truth predicate; but if we want to affirm some infinite lot of sentences then the truth predicate has its use. p. 12 
Gupta himself later makes explicit one of the 'component ideas of the [deflation$\operatorname{ary}^{1}$ ] theory...

The Infinite Conjunction Thesis: The truth predicate enables us to express certain infinite conjunctions and disjunctions' p.61

For example, the sentence 'what the Pope said is true' is a way of expressing the infinite disjunction (I) 'the Pope said that snow is white, and snow is white; or the Pope said that quarks exist, and quarks exist; or...'.

We will use Horwich's (1998) influential deflationary theory of the concept of truth:

(MT) The proposition that quarks exist is true iff quarks exist, the proposition that lying is bad is true iff lying is bad, . . . and so on (p.5)

Horwich writes:

the entire conceptual and theoretical role of truth may be explained on [the] basis of $\mathrm{MT}^{2}$

Call this the deflationary theory of truth or just deflationism. I am investigating what follows. In doing so, I set aside other deflationist theories. ${ }^{3}$ I am using Horwich's theory because it is a stripped back theory which is intended to give a highly restricted role to the concept of truth. I aim to show that even Horwich's theory allows the concept of truth to play an important explanatory role. This leads us to part (ii).

Part (ii) typically includes the claim that truth is not explanatory. In their Stanford Encyclopedia entry, Danial Stoljar and Nic Damnjanovic (2014) write:

[Some] philosophers have...suggested that...any kind of explanatory role is inconsistent with deflationism (Davidson 1990, Field, 1986, 1994). (Italics original)

Wyatt (2017) writes:

deflationists regularly contend that truth is 'non-explanatory'.

\footnotetext{
1 Gupta writes 'disquotational'.

2 Horwich also writes that the concept of truth 'contain[s] no more than what is expressed by uncontroversial instances of the equivalence schema, (E) It is true that p iff p' (Horwich 1998 p.6).

${ }^{3}$ I offer three reasons for setting them aside. First, there are too many. As Stewart (1998) notes 'There are as many - if not more -versions of deflationism as there are deflationist' p.501. Second, Horwich's theory is perhaps the most well-known and influential deflationist theory. (Sher (2016) focuses on Horwich in a recent overview of deflationism.) Third, recent theories which are advertised as deflationist allow more work to be done with the concept of truth than Horwich seems willing to allow (e.g. Picollo and Schindler 2018).

4 Wyatt cites Bar-On, Horisk \& Lycan (2000: 13-14), Brandom (2005), Devitt (1991), Field (1986: 67, 76, § §4.2-5.4; 1994: Postscript, §7), Grover (1992: §3.1), Horsten (2011: §7.4), Horwich (1998b: ch. 3; 2010: 6-7, 13-16), Künne (2008: §13), Leeds (1978: esp. § §III and IV), Lynch (2009: 107, 111) and Shapiro (1998). (Though it is not clear to me that the view can be ascribed to all these authors.) Similarly, Will Gamester (2018) writes 'the deflationist has traditionally offered seductive individualised explanations that seem to leave no explanatory work for truth' (p. 1264).
} 
Others ascribe to deflationism a slightly more circumscribed view. Michael Lynch (2009) offers three core tenets of deflationary theories, one of which is that.

the role of the truth concept is expressive not explanatory. Truth does not play a significant explanatory role. By a "significant" explanatory role, I mean that truth doesn't figure in any explanations except in its role as a useful generalization device. ${ }^{5}$ (p.107)

Jamin Asay (2013) offers two deflationary theses, one of which is that.

our concept of truth is explanatorily impotent. According to this thesis, our concept of truth serves merely an expressive function, not an explanatory one.

For Lynch and Asay, non-explanatoriness seems to be taken to be part of the definition of deflationary truth.

Wyatt, Lynch and Asay are all critics of deflationism. It is not as easy to find deflationists who explicitly endorse the view that deflationism is non-explanatory, but one who does is Michael Williams (1999), and he ascribes the view to deflationists in general:

contemporary deflationists are in broad agreement: the function of truth talk is wholly expressive, thus never explanatory. ${ }^{6}$ p.547

These claims that the deflationary concept of truth is not explanatory face purported counter-examples. Consider the following explanation ${ }^{7}$ :

Antecedent conditions: Bob has a true belief about where the beer is (and Bob wants a beer ${ }^{8}$ )

Law: True beliefs tend to facilitate success

Explanandum: Bob gets a beer

Both the statement of the law and of the antecedent conditions include the concept of truth, and indeed it seems essential to the explanation that they include the concept of truth. It seems that deflationists cannot account for this explanation. Call this the Success Argument against deflationism.

(Two quick clarifications are useful here. First, we should distinguish the question of whether the deflationary concept of truth can be explained from the question of whether it can $d o$ any explaining. ${ }^{9}$ Following the Success Argument, we will focus

\footnotetext{
${ }^{5}$ Earlier in the book Lynch is less circumscribed; 'deflationism removes truth from our explanatory toolkit' (p.4).

${ }^{6}$ Bar-One and Simmons (2021) cite Williams and then reject deflationism on the grounds that truth is explanatory.

7 See Putnam (1978), Field (1986), Gupta (1993), Leeds (1995).

8 I'll suppress this in future.

9 These are not always distinguished. For example, (Williams 1999 p. 548) writes 'a philosopher who supposes that truth has important explanatory work to do...will want to explain what makes true sentences (propositions, beliefs, and the like) true.' But perhaps truth is an unexplained explainer (i.e. primitive). Asay (forthcoming) defends this type of primitivism, arguing that the concept of truth cannot be explained, but can explain. Bar-on and Simmons (2021) make the distinction between explainer and
} 
on the latter. Second, we can ask if the deflationary concept of truth can explain semantic facts, mathematical facts and/or scientific/empirical facts. ${ }^{10}$ Following the Success Argument, we will focus on the latter. So we will focus on whether the deflationary concept of truth can explain scientific/empirical facts such as the fact that Bob gets a beer. I will leave implicit in future that 'explanatory' means 'explanatory of scientific/ empirical facts'.)

How do deflationists respond to the Success Argument? In think the most promising response is to argue that deflationary truth can account for the explanation. This is the response I defend in this paper. But so far deflationists have not said much to defend this position, and what they have said does not seem to have made its mark. Horwich (1998 pp. 22-23) offers the most detailed discussion I know of, but he deals with an easier example which makes explicit the content of the agent's belief (namely that if Bill nods then Bill gets a beer). It's not clear how this applies to the explanation above where the content of the belief is not specified. Later in the book he offers a few sentences (p.44) which seem to be aimed at the Success Argument, but the discussion is highly compressed. ${ }^{11}$ At any rate, clearly Horwich has not prevented Wyatt, Lynch, Asay and other recent writers from saying that deflationary truth is non-explanatory. Indeed, they do not even seem to think the claim is controversial, making the comment in passing and apparently without fear of being contradicted.

My aim is to provide a deflationist answer to the Success Argument. I claim that we should not define deflationism in terms of non-explanatoriness; to the contrary, I claim that truth, even if deflationary, is explanatory. My plan is to fill out in detail the response suggested by Horwich (though I do not claim that he would endorse my position).

So let's back up. Why would anyone think that deflationary truth is not explanatory in the first place? After some general comments about explanation in the next section I will identify three reasons to worry about the explanatory power of the deflationary concept of truth and argue that the deflationist should not be worried. Indeed I will argue that the thesis that the concept of truth is a device for expressing an infinitely long sentence motivates the thesis that the deflationary concept of truth is explanatory. The deflationary concept of truth is an explanatory concept. ${ }^{12}$

\footnotetext{
Footnote 9 (continued)

explainee, and insist that according to deflationism 'our understanding of truth is exhausted by the deflationary account, and truth in turn has no role in explaining other concepts'. p.481.

${ }^{10}$ Some deflationists are happy to concede that truth is not conservative, and therefore does play a role in mathematical explanations (see Field 1999, Horsten 2009).

11 Field (2005 Section 7) offers a lengthier discussion, but he makes numerous controversial implicit assumptions about meaning.

12 I do not argue that deflationists are correct that the deflationary concept of truth is our ordinary language concept of truth. But if it is, it follows that our ordinary language concept of truth is explanatory. Thanks to a referee for this clarification.
} 


\section{Explanation}

What is an explanation? An explanation is an answer to a 'why' question. Hempel and Oppenheim open their classic (1948) paper by commenting that:

To explain the phenomena in the world of our experience, to answer the question "why?"...is one of the foremost objectives of all rational inquiry. p.135

My aim is to show how the deflationary concept of truth can be explanatory. My opponent holds that there is some necessary condition on explanation (or on best explanation, or on what is essential to explanation etc.) that cannot be met by the concept of deflationary truth. What is necessary for an explanation? What is needed to answer a 'why' question?

For Hempel and Oppenheim (1948),

'the explanans falls into two subclasses;

one of these contains... sentences... which state specific antecedent conditions;

the other is a set of sentences... which represent general laws' p.137

They added a number of necessary conditions, most notably that 'the explanandum must be a logical consequence of the explanans' p. $137 .{ }^{13}$

These necessary conditions were soon weakened. Scriven (1962 p. 198) argued that explanations need not contain laws, giving the example that we can explain the stain in the carpet by appeal to the spilling of an inkwell, even if we have no knowledge of the laws involved. Hempel himself later allowed that the explanandum did not have to be a logical consequence of the explanans, pointing out that 'accounts in terms of statistical laws...play a very important role in science [and] we have to acknowledge that they constitute explanations of a distinct logical character' (1965 p. 393). This suggests that explanations need only increase the probability of the explanandum (relative to the relevant probability model). Schaffer (2017 p.3) has recently argued that explanations require some kind of linking claim, which might be a law, but might also be a metaphysical principle, or an inference rule.

I don't want to commit to any controversial position on explanation. I merely want to draw attention to the contemporary view that the necessary conditions on explanation are lax; it is not hard to be an explanation. This should immediately raise doubts about the claim that the deflationary concept of truth cannot be explanatory. Given how easy it is to be an explanation, we need to know exactly why the deflationary concept of truth is not explanatory.

I will consider three worries about the explanatory power of the deflationary concept of truth:

1. devices for expressing infinitely long sentences cannot be explanatory (Sections 4 and 5).

\footnotetext{
13 We can distinguish explanations as acts of communication vs explanations as things in the world. Strevens (2008 p. 6-7) is among many who make this distinction. We focus on the former, following Hempel and Oppenheim, but my arguments could be adapted to the latter.
} 
2. concepts of metaphysically disunified properties cannot be explanatory (Sections 6 and 7). ${ }^{14}$

3. explanations that use the deflationary concept of truth are always inferior to alternative explanations which do not use the deflationary concept of truth. (Section 8).

I will argue that none of these worries stand up to scrutiny. Responding to them will give us a picture of how exactly the deflationary concept of truth is explanatory. The overall view is that the deflationary concept of truth is explanatory in the same way that the concept of an average is explanatory in science.

\section{Averages and Explanations}

Start with the claim that:

1. devices for expressing infinitely long sentences cannot be explanatory.

I offer a counterexample. I will argue that the concept of an average-used as a device for expressing an infinitely long sentence-can be explanatory.

Consider the concept of having an average of 2.4 planets per star. Suppose this concept applies to the galaxy. There are an infinite number of different ways the galaxy can have an average of 2.4 planets per star, which we can express with an open-ended disjunction:

(U) There are 12 planets and 5 stars; or 24 planets and 10 stars or...

Thus the concept of an average can be used as a device for expressing such an infinitely long sentence.

Can such a device be explanatory? Yes. Melia (1995), Yablo (2005) and Manley (2009) have all drawn attention to the fact that averages might appear in our best theories. Here are some examples (I leave implicit the auxiliary assumptions needed for these to be complete explanations $)^{15}$ :

The galaxy has an average of 2.4 planets per star

Therefore the probability of extra-terrestrial life in the known universe is 0.1

Point $\mathrm{p}$ is the centre of mass of the solar system

Therefore Earth orbits around $p$

Global temperatures have been increasing

Therefore polar ice caps have shrunk

Finches with long beaks were fitter than finches with short beaks

Therefore finches with long beaks increased in frequency

\footnotetext{
${ }^{14}$ It remains open that there is some other account of why deflationary truth is not explanatory that remains to be developed.

15 Thanks to Michael Weisberg and John Matthewson for these examples.
} 
The centre of mass is the average position of matter in a system. Temperature is approximately the average energy per degree of freedom. The fitness of long beaks is the average fitness of long beaks across all the genotypes it finds itself in. ${ }^{16}$ So in all four cases, the first line expresses an average which explains the second line.

Therefore devices used for expressing infinitely long sentences can be explanatory. So we cannot rule out as non-explanatory all devices for expressing infinitely long sentences. So (even) given that the deflationary concept of truth is just a device for expressing infinitely long sentences, we cannot rule it to be non-explanatory.

Someone might object that not all uses of the concept of an average are used as devices for expressing infinitely long sentences. But I only need one counterexample. I only need one use of a device that expresses an infinitely long sentence and is explanatory. The counterexample refutes: 1. devices for expressing infinitely long sentences cannot be explanatory.

\section{Averages and Truth}

It was thinking about the connection between the deflationary concept of truth and the concept of an average that led to this paper, and the analogy is worth developing. (I) has the same form of an open-ended disjunction as (U):

(I) The Pope said that snow is white, and snow is white; or the Pope said that quarks exist, and quarks exist; or...

Both the concept of an average and the deflationary concept of truth can be used as a device for expressing infinitely long sentences.

If the deflationary concept of truth plays a role in explanation, it is a very similar role to that played by the concept of an average. The explanation of why the Earth orbits around point $p$ is that $p$ has the property of being the average location of mass in the universe. And to say that $p$ has the property of being the average location of mass in the universe is to say that:

There are [x1 kilograms of mass at 11, and x2 kilograms of mass at 12] or [y1 kilograms of mass at 11, and y2 kilograms of mass at 12] or...etc.

Similarly, the explanation of why a belief tends to cause successful action is that the belief has the property of being true. And to say that the belief has the property of being true is to say that:

[the belief b has content p, and p] or [the belief has content q, and q] or...etc.

Someone might object that the deflationary concept of truth is more than just a device for expressing infinitely long sentences. Fine. That makes it more likely that the concept can be explanatory. My point is that even if we concede that the concept

$\overline{16}$ See Rosenberg and Bouchard (2015). 
of truth is merely a device for expressing infinitely long sentences, it can still be explanatory.

\section{Gupta's Objections to Deflationist Explanation}

In this section I will discuss the second argument for the claim that the deflationary concept of truth is not explanatory (Gupta, 1993). I think the underlying worry is that:

2. concepts of metaphysically disunified properties cannot be explanatory.

I will argue that concepts of metaphysically disunified properties (e.g. deflationary truth) can be explanatory, even though they do not provide unified explanations. Then in the next section I focus on what it is for properties and explanations to be unified.

Let's first back up. The Success Argument says that the concept of truth plays an explanatory role in laws such as:

[6] True beliefs tend to facilitate success. ${ }^{17}$

So the true beliefs of an agent could explain her success.

The deflationist would suggest understanding (6) as an abbreviation of an infinitely long sentence, something like:

[8] [Believing that quarks exist iff quarks exist] tends to facilitate success, and [believing there is beer in the fridge iff there is beer in the fridge] tends to facilitate success and.... ${ }^{18}$

Gupta's objection to deflationism is that [8] fails to explain everything that needs explaining. Gupta agrees that (8) explains some things. ${ }^{19}$ For example, if we want an explanation of why Bob's going to the fridge for beer is successful, we can offer the facts that Bob believes there is beer in the fridge and that there is beer in the fridge. So [8] explains why.

[9] Bob's action was successful,

and also explains why.

\footnotetext{
${ }^{17}$ I use Gupta's numbering.

18 A referee objects that [8] is not a good paraphrase of [6] on the grounds that having a random particular true belief does not tend to facilitate success. Let me give three quick responses. First, a flat-footed denial; I think having a random particular true belief does tend to facilitate success. This is plausible if we contrast an agent with a random true belief to an otherwise similar agent with a random false belief. The increased tendency towards success may be small, but it would still be there. Second, we might be able to define an infinitary connective that's true if most (weighted?) of its conjunts/disjuncts are true and use this to improve [8]. Third, if the deflationist cannot paraphrase [6] then the referee is offering a new problem for deflationism. The Success Argument is not that deflationism cannot express [6]; it's that when they do, they fail to explain everything that needs to be explained. So henceforth I will assume that [6] can be paraphrased as [8].

${ }^{19}$ Compare Horwich (1998 p.21-23).
} 
[10] Bob's action and Alice's action and Charlie's action etc... are mostly successful.

But Gupta objects that [8] fails to explain the overall success of actions based on true beliefs. [8] fails to explain why.

[11] Actions based on true beliefs are mostly successful.

Gupta argues that explaining all the instances of a generalization [10] is not sufficient for explaining the generalization [11]. More generally, 'to explain one of two sentences that are necessarily equivalent is not thereby to explain the other' p.66.

Gupta is clearly correct that explaining one sentence does not entail explaining a necessarily equivalent sentence; to explain why Cicero was denounced is not to explain why Tully was denounced (the hearer would have to know that Cicero is Tully). ${ }^{20}$ But Gupta needs to argue that in this specific case (i.e. of truth) there is an explanation for [11] that is not expressed by [8]. I will argue that there is not.

Gupta's main argument ${ }^{21}$ comes from the following example:

We can explain each instance of the generalization "everyone on the boat died" by providing a separate explanation for the death of each person on the boat: Jack died of a heart attack; Mohini drowned; etc. But these separate explanations do not necessarily explain the generalization. The generalization may in fact have no explanation at all - it may be true accidentally. Or it may have an altogether different explanation, such as that the boat capsized. In any case, an explanation of the instances is not necessarily an explanation of the generalization. p.67 Italics added

We can grant that an explanation of the instances does not necessarily explain the generalization. Nevertheless, an explanation of the instances can explain a generalization. With the background information that Jack and Mohini were the only people on the boat, the explanation of why each of them died does explain why everyone on the boat died. Similarly, the deflationist can hold that an explanation of the success of each action based on a true belief [8] does explain why actions based on true beliefs are mostly successful [11].

Someone might object that we are left positing some unlikely coincidence. If everyone on a boat dies of various disunified causes, that is an unlikely coincidence. By contrast, if true beliefs are successful, the success is surely not an unlikely coincidence.

\footnotetext{
20 So explanation is hyperintensional. See Schneider (2011), Nolan (2014).

21 Gupta makes two other points in passing. First, he says that 'The conjuncts of [10] are particular in character. So, [10] itself is particular in character. But this is not true of [11], which is general.' p.67 In response, I suggest that an infinite sequence of particular facts can explain a general fact.

Second, he says that '[11] gives us information about counterfactual situations that lie beyond the openended conjunction [10].' This, I think, is false. If [11] gives us information about counterfactual conditionals, then [10] should include every possible act based on a true belief, and so [10] describes counterfactual situations. As [10] is already open-ended, I see no reason to limit it to describing actual actions. The use of 'are' suggests that it is limited to actual actions, but we could modify this to [11*] 'Actions based on true beliefs in the actual, and nearby worlds, are mostly successful'.
} 
But we need not say it is. We can explain the generalization by explaining the instances; true beliefs tend to facilitate success because the belief that $\mathrm{p}$ tends to facilitate success if $\mathrm{p}$, and the belief that $\mathrm{q}$ tends to facilitate success if $\mathrm{q}$... etc.

Gupta draws our attention to unified explanations-[8] fails to be a unified explanation for [11]. But sometimes there is no unified explanation. If the boat capsizes and causes every death, there is a unified explanation for the deaths; however, if a series of unfortunate events causes each death, there is no unified explanation. That there is no unified explanation is exactly what the deflationist says about truth. ${ }^{22}$ Deflationists say that there is no unified explanation for [11]; there is only the disunified explanation that [8] [believing that quarks exist iff quarks exist] tends to facilitate success, and [believing there is beer in the fridge iff there is beer in the fridge] tends to facilitate success etc. Again, this doesn't mean there is a coincidence, it just means that the explanation goes up (to generalizations) rather than down (from generalizations).

This leads us to what is correct about the claim that the deflationary concept of truth cannot explain. The deflationary concept of truth does not provide a unifying explanation. I think this talk of unifying explanations is based on some metaphysical intuitions which should be brought to the surface and will be the focus of the next section.

If the last few paragraphs were obscure, an analogy might be helpful. Consider the debate between Humean and non-Humeans about laws of nature. According to the Humean view the world fundamentally consists of local matters of fact, and these local matters of fact explain generalizations like 'objects with mass attract'. Instances explain generalizations. According to some non-Humean views, laws are fundamental, and explain local matters of fact. Generalizations explain instances.

We can understand deflationism as analogous to the Humean view, where instances such as [9] 'Bob's action was successful' explain generalizations such as [11] 'Actions based on true beliefs are mostly successful'. And we can understand one version of the correspondence theory of truth as analogous to non-Humean theories, with generalizations explaining instances. ${ }^{23}$

\section{Disunified Explanations and the Property of Truth}

We have arrived at the heart of the second account of what might be wrong with deflationary truth - that deflationary truth is disunified, and explanations must be unified.

It is really the unity of the properties which is at issue here, and to make sense of unified properties we need some heavy duty metaphysics. Here is a familiar, if not

\footnotetext{
22 E.g. Horwich (1998, 2010 p.6).

23 Admittedly, Humean theories face the objection that it makes regularities a fluke (Strawson 1989, p.21). But notice that for each true belief, there will be an explanation of why it leads to success in terms of appropriate behaviour. There will be no such explanation for the movement of a particle for the Humean. I leave for another occasion a discussion of the significance of the analogy for deflationists.
} 
entirely uncontroversial, story which I will assume (see Lewis, 1983, 1986; Schaffer, 2004).

Fundamental properties serve as an ontological base. They are not instantiated in virtue of anything else. They ground all higher level properties.

Example: We don't know what the fundamental properties are, but spin and mass are current contenders. ${ }^{24}$

Natural properties ground objective similarities and carve out causal powers.

Example: The property of believing that grass is green is natural, as believers that grass is green have behavioural patterns in common. Properties can be more or less natural. ${ }^{25}$ The maximally natural properties are the fundamental properties.

Abundant properties provide the semantic values of meaningful predicates. The abundant properties may be as extrinsic, as gruesomely gerrymandered, as miscellaneously disjunctive as you please.

Example: The property of being-the-Eiffel-Tower-or-my-nose is abundant. Abundant properties include fundamental and natural properties

There is a sense in which most abundant properties are disunified. But I want to define a more specific sense of disunified:

Property $\mathrm{p}$ is disunified iff $\mathrm{p}$ is not fundamental and there is no finitely expressible way to characterize $\mathrm{p}$ in terms of more natural properties.

To take an example, the justified-true-belief theory of knowledge (S knows p iff $\mathrm{S}$ has a justified true belief that $\mathrm{p}$ ) can be understood as a conceptual analysis of the concept of knowledge. But we could transpose this theory about the concept of knowledge into a theory about what grounds the property of knowing ${ }^{26}$ i.e. knowing is grounded by the conjunction of the more natural properties of believing, being true and being justified. If so, knowledge is not disunified. By contrast, one might hold that there is no way to characterize knowledge in terms of more natural properties, in which case knowledge is disunified. (Either because the justifiedtrue-belief theory fails, or because justification/truth/belief are not more natural than knowledge.)

I suggest that the deflationary concept of truth entails ${ }^{27}$ the thesis that the property of truth is disunified. ${ }^{28}$ As written, this theory of the property of truth looks like the same open-ended disjunction as Horwich's theory of the concept of truth:

\footnotetext{
24 I set aside the onion universes that motivate Schaffer (2004).

25 See Lewis (1984 p. 228), also (1986 p. 61); see also Dorr and Hawthorne (2013 p. 19) and Bradley (2020a, 2020b).

26 Compare the 'real definition' of Fine (1994).

27 Assuming the plausible thesis that the propositions in MT are disunified.

28 See Horwich (2005: 70; 1998: 52 2010: 14; 2013:57). For arguments that truth is not a fundamental property, see Schaffer (2008 p.308) and Asay (2014). This theory of truth is has echoes of McDowell's (1981, 202) 'shapelessness thesis' (so named by Simon Blackburn (1981) and Markosian's (1998) 'Brutalism'.
} 
(MT) The proposition that quarks really exist is true iff quarks really exist, the proposition that lying is bad is true iff lying is bad, ... and so on

but we now understand MT as expressing what grounds the property of being true. $^{29}$

Can concepts of disunified properties be explanatory? I think so. I will argue that concepts of highly non-natural properties can be explanatory; if so, it is very plausible that concepts of disunified properties can be explanatory.

Sider (2011) is a prominent advocate of requiring concepts of natural properties in explanation, but even he adds various hedges in his most explicit comment: " "theories" based on bizarre, non-joint carving classifications are unexplanatory even when true' p.23 (italics added). ${ }^{30}$

But non-joint carving theories need not be bizarre. It is plausible that higher level sciences like biology and economics are non-joint carving, but still not bizarre. They refer to properties which are multiply realizable, but surely they are explanatory (see Jackson \& Pettit, 1990a, 1990b; Damnjanovic, 2004).

Sider writes that 'the notions of the special sciences carve at the joints reasonably well.' p. 23 But that seems wrong. Take an economic property like money. Almost every substance imaginable could be used as money by some agents in some system. In the actual world, money includes gold, paper, tobacco and patterns of magnetized metal. Money does not carve at the joints. ${ }^{31}$

Furthermore we can give explanations in highly non-natural terms at will. ${ }^{32}$ Take the paradigm non-natural property, grue. Suppose magpies are attracted to both green and blue objects. Then we might explain why a magpie stole my emerald by citing its being grue. Given that concepts of highly non-natural properties can be explanatory, we can plausibly take the further step and say that concepts of disunified properties can be explanatory. The concept of an average provides an example. So the disunity of the property of truth is no obstacle to the concept of truth being explanatory.

Someone might object that natural/unified properties provide for better explanations. In the example above, they might claim that a better explanation of why a magpie stole my emerald is that it is green. But why would that be better? This leads to the topic of the next section, the third argument against deflationism. I will argue that explanations with fewer details can be better than explanations with more details.

\footnotetext{
${ }^{29}$ This theory would contrast with, say, a correspondence theory which says that truth is grounded in correspondence with the world. This is often how the correspondence theory seems to be understood. For example, in his Stanford Encyclopedia entry, Marian David (2015) gives the objection that 'the correspondence relation is mysterious', asking 'what physical relation could it be?'. The objection seems to be that the correspondence theory fails to reduce truth to fundamental properties i.e. physical properties.

${ }^{30}$ See also Strevens (2008) and Hazlett (2017).

${ }^{31}$ Sider later argues (Section 7.11.1) that functional properties can carve at the joints reasonably well. Even if so, I'm not sure if this argument could be extended to deflationary truth.

${ }^{32}$ See Taylor (2015 p.322).
} 


\section{The Explanatory Superiority of Deflationary Truth}

Let's assume that we have established that the deflationary concept of truth can be an essential part of scientific/empirical explanations. A fall-back position is available for those unhappy with deflationist explanations:

3. explanations that use the deflationary concept of truth are always inferior to alternative explanations which do not use the deflationary concept of truth.

That is, the objector may concede that the deflationary concept of truth can be explanatory, but hold that there is always a better explanation to be given that does not mention truth.

For example, compare two explanations of why Bob succeeded in getting a beer. On the one hand, we have an explanation which uses the concept of truth:

a-. Bob had a true belief about where the beer was

Making explicit the deflationary concept of truth, we have:

a. [There was beer in the fridge and Bob believed that there was beer in the fridge] or [There was beer in the cupboard and Bob believed that there was beer in the cupboard] or...

On the other hand, here is an explanation which makes no use of the concept of truth (nor any infinitely long sentences):

b. There was beer in the fridge and Bob believed that there was beer in the fridge.

The objector could argue that $\mathrm{b}$ is a better explanation. After all, it includes the additional detail that the beer was in the fridge. And perhaps this shows that explanations stating the specific belief are better than explanations that make more general claims involving truth-the appeal to truth abstracts away from what really does the explaining.

However, a familiar point from the philosophy of science literature is that abstracting away from details can improve an explanation. Putnam (1975: 295-97) famously argued that the reductive microphysical explanation of why a square peg doesn't fit through a round hole is not a good explanation. A good explanation includes only the relevant details, captures the underlying generalizations and in this case should be put in terms of the higher level geometric structure:

[I]f you are not 'hipped' on the idea that the explanation must be at the level of the ultimate constituents,...then there is a very simple explanation here. The explanation is that the board is rigid, the peg is rigid, and as a matter of geometrical fact, the round hole is smaller than the peg, the square hole is bigger than the cross-section of the peg. The peg passes through the hole that is large enough to take its cross-section, and does not pass through the hole that is too small to take its cross-section. That is a correct explanation whether the peg consists of molecules, or continuous rigid substance, or whatever. 
There are many other examples which motivate various forms of functionalism and non-reductionism. ${ }^{33}$

In our case, Bob's success in getting a beer can be explained by his true belief about where the beer is - whether the beer is in the fridge, or in the cupboard, or wherever. Therefore, not only can the deflationary concept of truth be explanatory, it could be part of a better explanation than one that appeals to specific beliefs.

There are various theories about why removing details improves explanations. One theory is that explanations with fewer details are more robust across possibilities, and robustness is a virtue of explanations. In our case, the explanation in terms of truth is more robust, in that the explanation would survive even if the beer were in a different place. By contrast, an explanation that specifies that the beer is in the fridge becomes false if the beer is in the cupboard, so the purported explanation fails. So an explanation with fewer details might be better for explaining more phenomena (Jackson \& Pettit, 1990a; Jones 2018).

Another theory of why explanations with fewer details can be better is that explanation is contrastive, so the explanation has to be of the right level of generality to fit the explanandum. In our case, if we want to know why Bob got a beer, rather than failed to get a beer, then we need to know whether Bob has true beliefs about the beer rather than false beliefs about beer. We don't need to know whether the beer is in the fridge or the cupboard. So if we are interested in agents' overall success, it is having true beliefs that matters, not the content of the beliefs (Schaffer 2005; Franklin-Hall 2016).

A third theory is that logically stronger explanations are better, and that (a) is stronger than (b) because (a) omits details from the antecedent. (b) tells us that in the specific situation where the beer is in the fridge, Bob gets beer. (a) tells us that in any situation where Bob wants beer (and has access to where it is, has no conflicting over-riding desires etc.), Bob gets beer. So (a) is logically stronger than (b) and this might be why (a) is a better explanation (Bradley, 2020b).

Any of these accounts can be applied here, so we can remain neutral on which is correct. We need only the assumption that omitting details can improve an explanation to arrive at the conclusion that the deflationary theory of truth can improve an explanation.

\section{Conclusion}

It is widely agreed that the deflationary concept of truth is not explanatory. I have argued that it is. The deflationary concept of truth can be understood on the model of the concept of averages. Both can be explanatory. Furthermore, I have argued

\footnotetext{
33 Alan Garfinkel (1981) argues that the best explanation of changes in rabbit populations do not make reference to the details of which rabbits were eaten by which foxes. Jerry A. Fodor (1987, 3-4) argues that if you want to explain his behaviour, you should work with his (high-level) desires and beliefs, rather than his (low-level) neurological states. Jackson and Pettit (1990a, 1990b) argue that a conductor's annoyance is better explained by the fact that someone is coughing than by the fact that Bob is coughing (assuming the conductor doesn't have a particular dislike of Bob).
} 
that the deflationary concept of truth suggests a theory of the property of being true. Truth can be understood as a metaphysically disunified property. Such a property is found by abstracting away from details. And abstracting away from details can improve explanations, suggesting that metaphysically disunified properties can play an important role in our theorizing. This suggests that we should reject the standard conception of deflationary truth, which combines a minimalist theory of the concept with the thesis that the concept is not explanatory. And we should also reject the standard taxonomy which contrasts explanatory substantive theories of truth with deflationary non-explanatory theories of truth. Deflationary truth is explanatory.

Open Access This article is licensed under a Creative Commons Attribution 4.0 International License, which permits use, sharing, adaptation, distribution and reproduction in any medium or format, as long as you give appropriate credit to the original author(s) and the source, provide a link to the Creative Commons licence, and indicate if changes were made. The images or other third party material in this article are included in the article's Creative Commons licence, unless indicated otherwise in a credit line to the material. If material is not included in the article's Creative Commons licence and your intended use is not permitted by statutory regulation or exceeds the permitted use, you will need to obtain permission directly from the copyright holder. To view a copy of this licence, visit http://creativecommons.org/licen ses/by/4.0/.

\section{References}

Armour-Garb, B., \& Beall, J. C. (Eds.). (2005). Deflationary truth. Open Court.

Asay, J. (2014). Against truth. Erkenntnis, 79(1), 147-164.

Asay, J. (2021). Primistivism about truth. In M. P. Lynch, N. Kellen, J. Kim, \& J. Wyatt (Eds.), The nature of truth: Classic and contemporary perspectives. Camb: MIT Press.

Ayer, A. J. (1946). Language, truth, and logic. Gollancz.

Bar-On, D., Horisk, C., \& Lycan, W. (2000). Deflationism, meaning, and truth-conditions. Philosophical Studies, 101, 1-28. Reprinted with postscript in Armour-Garb and Beall (2005), 321-52.

Bar-On, D., \& Simmons, K. (2021) The use of force against deflationism: Assertion and truth. The Nature of Truth: Classic and Contemporary Perspectives, 475.

Blackburn, S. (1981). Rule-following and moral realism. In S. Holtzman \& C. Leich (Eds.), Wittgenstein: To follow a rule (pp. 163-87). Routledge.

Bradley, D. (2020a). Naturalness as a constraint on priors. Mind, 129(513), 179-203.

Bradley, D. (2020). Should explanations omit the details? British Journal for the Philosophy of Science, $71,827-853$.

Brandom, R. (2005). Expressive versus explanatory deflationism about truth. In Armour-Garb and Beall (pp. 237-57).

Damnjanovic, N. (2004). Deflationism and the success argument. The Philosophical Quarterly, 55(218), 53-67.

David, M. (2020). The correspondence theory of truth. In E. N. Zalta (Ed.), The Stanford Encyclopedia of Philosophy (Winter 2020 Edition). https://plato.stanford.edu/archives/win2020/entries/truth-corre spondence/.

Devitt, M. (1991). Realism and truth (2nd ed.). PUP.

Edwards, D. (2013). Truth as a substantive property. Australasian Journal of Philosophy, 91(2), $279-294$.

Field, H. (1986). The deflationary conception of truth. In G. MacDonald \& C. Wright (Eds.), Fact, science, and morality (pp. 55-117). Blackwell.

Field, H. (2005). Postscript to 'deflationist views of meaning and content'. In B. Armour-Garb, \& J. C. Beall (Eds.), Deflationary truth (pp. 92-110).

Fine, K. (1994). Essence and modality. Philosophical Perspectives, 8, 1-16. 
Gamester, W. (2018). Truth: Explanation, success, and coincidence. Philosophical Studies, 175(5), pp. 1243-1265. ISSN 0031-8116

Grover, D. (1992). A Prosentential Theory of Truth. Princeton.

Gupta, A. (1993). A critique of deflationism. Philosophical Topics, 21(2), 57-81.

Dorr, J. H. C. (2013). Naturalness. In D. W. Zimmerman \& K. Bennett (Eds.), Oxford studies in metaphysics (Vol. 8, pp. 3-77). Oxford University Press.

Horsten, L. (2011). The Tarskian turn: Deflationism and axiomatic truth. MIT Press.

Horwich, P. (1998). Truth (2nd ed.). OUP.

Jackson, F., \& Pettit, P. (1990a). Program explanation: A general perspective. Analysis, 50(2), 107-117.

Jackson, F., \& Pettit, P. (1990b). Causation in the philosophy of mind. Philosophy and Phenomenological Research, 50, 195-214.

James, W. 1907 [1975]. Pragmatism: A new name for some old ways of thinking. Longmans, Green \& Co.; reprinted Cambridge, MA: Harvard University Press.

Kripke, S. A. (1982). Wittgenstein on rules and private language. Harvard University Press.

Künne, W. (2003). Conceptions of truth. OUP.

Leeds, S. (1978). Theories of truth and reference. Erkenntnis, 13(1), 111-129.

Leeds, S. (1995). Truth, correspondence, and success. Philosophical Studies, 79(1), 1-36.

Lewis, D. (1983). New work for a theory of universals. Australasian Journal of Philosophy, 61(4), 343-377.

Lewis, D. (1986). Events. In Philosophical papers (Vol. II). Oxford University Press.

Lewis, D. (1994). Reduction of mind. In S. Guttenplan (Ed.), A companion to philosophy of mind (pp. 412-431). Blackwell Publishers. Republished in Philosophy of Psychology: Contemporary Readings Bermudez (ed.) and in Philosophy of Mind: Contemporary Readings (O'Connor and Robb (eds.)

Lewis, D. (2001). Forget about the 'correspondence theory of truth.' Analysis, 61(272), 275-280.

Lynch, M. (2009). Truth as one and many. OUP.

Manley, D. (2009). When best theories go bad. Philosophy and Phenomenological Research, 78(2), 392-405.

Markosian, N. (1998). Brutal composition. Philosophical Studies, 92, 211-249.

McDowell, J. (1981). "Non-cognitivism and rule-following", reprinted in his Mind, value, and reality (pp. 198-219). Harvard University Press.

Melia, J. (1995). On what there's not. Analysis, 55, 223-229.

Nolan, D. (2014). Hyperintensional metaphysics. Philosophical Studies, 171(1), 149-160.

Pedersen, N. J. L. L., \& Wright, C. (Eds.). (2013). Truth and pluralism: Current debates. Oxford University Press.

Pedersen, N., \& Wright, C. D. (2016). Pluralist theories of truth. In E. N. Zalta (Ed.), The stanford encyclopedia of philosophy (Spring 2016 Edition). https://plato.stanford.edu/archives/spr2016/entries/ truth-pluralist/.

Picollo, L., \& Schindler, T. (2018). Disquotation and infinite conjunctions. Erkenntnis, 83(5), 899-928.

Putnam, H. (1978). Meaning and the moral sciences (pp. 15-17). Routledge, Kegan Paul.

Quinton, A. (1957). Properties and classes. Proceedings of the Aristotelian Society, 58, 33-58.

Ramsey, F. (1927). Facts and propositions. Proceedings of the Aristotelian Society Supplementary, 7(1), $153-170$.

Rosenberg, A., \& Bouchard, F. (2015). Fitness. In E. N. Zalta (Ed.), The stanford encyclopedia of philosophy (Fall 2015 Edition). https://plato.stanford.edu/archives/fall2015/entries/fitness/.

Schaffer, J. (2004). Two conceptions of sparse properties. Pacific Philosophical Quarterly, 85(1), 92-102.

Schaffer, J. (2017). The ground between the gaps. Philosophers' Imprint, 17, 1-26.

Scriven. (1962). Explanations, predictions, and laws. In H. Feigl \& G. Maxwell (Eds.), Minnesota studies in the philosophy of science. Univ. of Minnesota Press.

Shapiro, S. (1998). Proof and truth: Through thick and thin. Journal of Philosophy, 95(10), 493-521.

Schnieder, B. (2011). A logic for 'because.' The Review of Symbolic Logic, 4(3), 445-465.

Sider, T. (2011). Writing the book of the world. Oxford University Press.

Stoljar, D., \& Nic, D. (2014). The deflationary theory of truth. In E. N. Zalta (Ed.), The Stanford encyclopedia of philosophy (Fall 2014 Edition). https://plato.stanford.edu/archives/fall2014/entries/truthdeflationary/.

Strevens, M. (2008). Depth: An account of scientific explanation. Harvard University Press.

Taylor, E. (2016). Naturalness in Context. Inquiry, 59(4), 1-24.

Väyrynen, P. (2014). Shapelessness in context. Nô̂s, 48(3), 573-593. 
Wittgenstein, L. (2010). Philosophical investigations. Wiley.

Wyatt, J. (2016). The many (yet few) faces of deflationism. Philosophical Quarterly, 66(263), 362-382.

Yablo, S. (2005). The myth of the seven. In M. Kalderon (Ed.), Fictionalism in metaphysics. Oxford: Oxford University Press.

Publisher's Note Springer Nature remains neutral with regard to jurisdictional claims in published maps and institutional affiliations. 